\title{
Using Outcomes Data to Justify Instituting ASC-NSQIP and New Technology
}

\section{Starker $\mathrm{PM}^{1}{ }^{*}$ and Chinn $\mathrm{B}^{2}$}

${ }^{1}$ Overlook Medical Center, Columbia University Vagelos College of Physicians and Surgeons, New York, USA

${ }^{2}$ Division of Colon and Rectal Surgery, Overlook Medical Center, Robert Wood Johnson Medical School, NJ, USA

*Corresponding author: Paul M Starker, Chairman of Surgery, Overlook Medical Center, Clinical Professor of Surgery, Columbia University Vagelos College of Physicians and Surgeons, New York, USA, Tel: 9086089001; E-mail: pmstarker@att.net

Received date: March 19, 2018; Accepted date: March 24, 2018; Published date: March 29, 2018

Citation: Starker PM, Chinn B (2018) Using Outcomes Data to Justify Instituting ASC-NSQIP and New Technology. Colorec Cancer. Vol.4 No.1: 3.

Copyright: (C) 2018 Starker PM, et al. This is an open-access article distributed under the terms of the Creative Commons Attribution License, which permits unrestricted use, distribution, and reproduction in any medium, provided the original author and source are credited.

\section{Short Communication}

The United States (U.S.) continues to experience a shift in the federal and private insurance payer's reimbursement systems from the historical "pay for volume" to today's "pay for value" model [1]. This is evidenced by the fact that the U.S. Department of Health and Human Services (HHS) plans to link $90 \%$ of all Medicare fee-for-service reimbursements to "quality or value" by the end of 2018 and plans to have $50 \%$ of Medicare payments tied to "quality or value" through alternative payment models by the end of 2018 [2-4].

Furthermore, the Centers for Medicare and Medicaid Services (CMS) established two new programs, the Hospital Acquired Condition Reduction program (HACRP) [5] and Readmissions Reduction Program (HRRP) [6], as part of the effort to aggressively move toward paying for high performance rather than paying for volumes of services. In 2017, CMS reported that 769 U.S. hospitals were penalized for hospital acquired conditions [7]. Beginning on October 1, 2012 under the HRRP, CMS began to significantly reduce reimbursement to hospitals for excessive readmissions [6]. Under the terms of this program, CMS makes hospital and individual physician performance data public and easily searchable.

Therefore, the ability to demonstrate quality or value is increasingly important and ultimately remains the responsibility of the hospital and the physician. In order for hospitals and physicians to perform at a high-level within this new payment system, the definition of "value" must be clearly understood by all. Value can be assessed with the simple equation of a quality to cost ratio (i.e., quality over cost). Value therefore can be impacted by either decreasing costs or increasing quality. However, one's ultimate goal in striving for maximum value should be to simultaneously decrease costs and increase quality.

Although decreasing costs is extremely difficult in the healthcare environment, there are certain areas where changes can be made to affect spending. Companies who provide lower priced equipment and drugs can be found, fewer diagnostic tests can be performed, and changes in surgical technique allowing for cost savings can be made.
However, there is a limit to how much cost can actually be cut out of the current healthcare delivery system without negatively impacting patient outcomes. Therefore, to make any major impact on value, providers must focus on improving quality which can be achieved with the National Surgical Quality Improvement Program and/or by adopting technology with a favorable performance profile (e.g., ability to reduce post-operative complications, improve patient quality care, etc.).

\section{The Value of NSQIP}

The most useful surgical benchmarking performance database available today is the one provided by the American College of Surgeons and known as the National Surgical Quality Improvement Program (ACS NSQIP ${ }^{\circledR}$ or NSQIP). In 2010, Overlook Medical Center (OMC) enrolled in the NSQIP database to identify areas of opportunity for improvement and encourage process changes to reduce the potential for these post-operative occurrences. One of these areas was Superficial Surgical Site Infections (SSIs) in General and Colorectal Surgery (Figure 1). Using the program to follow progress, OMC was able to attain a remarkable decrease in surgical site infection rates.

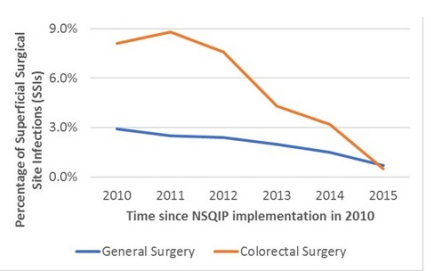

Figure 1 Reductions in Superficial SSIs in General and Colorectal Surgery, 2010-2015.

\section{Multiple process changes were implemented in an effort to achieve these improvements}

- Operating room (OR) traffic was decreased, 
- OR attire and hair covers were standardized (scrubs were laundered in hospital),

- Prep solutions were changed to alcohol-based product,

- Personal belongings (such as brief cases) were no longer allowed in the OR,

- Priority placed on daily terminal cleaning of all OR rooms,

- Improved preoperative and intraoperative attention to glucose control,

- Appropriate management of contaminated wounds,

- Preoperative patient showers with chlorhexidine,

- Re-dosing of antibiotics in the O.R., if the procedure time exceeded 4 hours.

\section{In addition to the above list, colorectal surgery process changes also included}

- Preoperative mechanical and oral antibiotic preparations,

- Wound protectors,

- Closing trays.

Complications and infection rates reduced over time and have saved OMC enough money to fund the NSQIP program. As a result, the program clearly demonstrated great value.

\section{The Value of Technology Adoption}

Technology adoption is another means by which to improve value. The same evaluation that was performed in looking at the cost of implementing and maintaining the NSQIP database must be done when determining the value of acquiring technology. Similar to the NSQIP program, technology acquisition comes at a cost, but if an increase in quality can offset that cost, then value can be achieved.

One such technology is the SPY Elite Fluorescence Imaging System (NOVADAQ Technologies ULC, now a part of Stryker Corporation, San Jose, California) for use in open and minimally invasive surgery. The benefits of SPY technology have been featured in more than 290 peer-reviewed publications in the medical literature. SPY technology is available in a variety of platforms including the PINPOINT Endoscopic Fluorescence Imaging System. PINPOINT allows real-time evaluation of vascular blood supply to various anatomic structures during laparoscopic surgical procedures. One important application for PINPOINT is the microvascular assessment of blood flow to the colon both before resection and after reconstruction at the planned site of anastomotic creation. It is well documented that post-operative anastomotic failure is often related to ischemia, and therefore, vascular evaluation at the time of selection of the site for colon transection would theoretically allow surgeons to appreciate the potential for a poorly perfused anastomosis. Most importantly, this appreciation would enable surgeons to immediately make revisions while in the operating room in an effort to prevent anastomotic failure days later.

The results of the PILLAR II study, published in 2014, concluded that the PINPOINT system is a safe and feasible tool for intraoperative assessment of tissue perfusion during colorectal resection, and that it may lead to a decreased incidence of anastomotic leak [8]. This feasibility study analyzed 139 patients undergoing low anterior resection (mean level of anastomosis was $10+4 \mathrm{~cm}$ from the anal verge). The use of PINPOINT contributed to a change in surgical plan related to planned anastomosis in $11(8 \%)$ patients. The overall anastomotic leak rate in the study was $1.4 \%(\mathrm{~N}=2)$, with no leaks in the 11 patients who had a change in surgical plan based on intraoperative fluorescence imaging assessment with PINPOINT. These results were the impetus to proceed with PILLAR III, an ongoing, controlled, randomized trial looking at a similar patient population at 25 major hospital systems throughout the United States.

Our recent study at Overlook Medical Center (OMC) validated PILLAR II trial results by confirming PINPOINT's safety profile and effectiveness as an intraoperative assessment tool during colorectal resection and also showed a decreased incidence of anastomotic leaks in those assessed with PINPOINT [9]. The costs of the equipment and the cost of the disposables to perform PINPOINT intraoperative imaging were offset by the improved quality and subsequent cost savings associated with its use after just 143 colon resections.

Prior to the adoption of NSQIP and PINPOINT, patients whom experienced anastomotic failure at OMC developed various complications which contributed to increased direct costs (e.g., supply costs, staff salaries, operating room and hospital room charges) based on calculations from the NSQIP database (Table 1).

Table 1 Factor by which direct costs increased as a result of post-operative complications in patients who suffered an anastomotic failure.

\begin{tabular}{|l|l|}
\hline $\begin{array}{l}\text { Anastomotic Failure Associated } \\
\text { Complications }\end{array}$ & $\begin{array}{l}\text { Factor by which direct costs } \\
\text { increased as a result of } \\
\text { Anastomotic Failure Associated } \\
\text { Complications }\end{array}$ \\
\hline Severe Sepsis & $4.27 x$ \\
\hline $\begin{array}{l}\text { Cather-Associated Urinary Tract } \\
\text { Infection (CAUTI) }\end{array}$ & $3.13 x$ \\
\hline $\begin{array}{l}\text { Deep Vein Thrombosis (DVT) } \\
\text { Organ Space Colon-Related } \\
\text { Surgical Site Infection (SSI) }\end{array}$ & $3.36 \mathrm{x}$ \\
\hline
\end{tabular}

Table 1 lists the various complications developed by patients experiencing anastomotic failure at OMC and the associated contribution to increased direct costs based on calculations from the NSQIP database. These complications mirror those that carry potential for institutional financial penalties under the previously mentioned programs. Therefore, although not directly quantifiable, a reduction in these complications will lead to decreased costs and increased hospital reimbursement. This again supports using the value equation as a guide when making decisions related to acquiring and committing to quality improvement databases such as NSQIP or technology to justify initial cost expenditures when striving to improve value. 
Finally, the premise of value-based purchasing is soon to be applied to individual providers and not just healthcare institutions. Pay-for-performance (P4P) measures will be applied to physicians in the near future. Physician income will be withheld from Medicare reimbursements and paid back based on newly developing parameters starting with $4 \%$ in 2019 and going to $9 \%$ by 2022 [10]. Although the exact parameters are still not definite, it is clear that quality and resource utilization will make up roughly $50 \%$ of the equation [10].

In summary, the future of healthcare reimbursement is clear. The basis of medical reimbursement is going to become more and more dependent on value rather than volume. It is essential for physicians and hospital administrators to reevaluate the methods by which they perform financial analyses and allocate funds for new projects, programs and technologies targeted at quality improvements, so a clear potential for return on investment can be determined. These evaluations no longer consist of merely assessing the impact of acquisitions on the volume of patients they can affect, but rather on whether or not their use will generate value. It is very clear that value is dependent on quality. So, in today's environment, anything (e.g., a program or technology) that elevates the level of quality for the organization or individual will lead to an increase in value and subsequently, must be thought of as economically favorable.

\section{References}

1. Centers for Medicare \& Medicaid Services (2015) CMS Quality Measure Development Plan: Supporting the Transition to the Merit-based Incentive Payment System (MIPS) and Alternative Payment Models (APMs) (DRAFT). Baltimore, MD: Centers for Medicare \& Medicaid Services (https://www.cms.gov/ Medicare/Quality-Initiatives-Patient-Assessment-Instruments/ Value-Based-Programs/MACRA-MIPS-and-APMs/MACRA-MIPSand-APMs.html) Accessed on March 13, 2018.
2. Bendix J (2015) From quantity to quality: Meeting the new demands of value-based care. Medical Economics 92: 26-32.

3. Burwell S (2015) Setting Value-Based Payment Goals - HHS Efforts to Improve U.S. Health Care. New England Journal of Medicine 372: 897-899.

4. U.S. Health Policy Gateway (2017) (http:// ushealthpolicygateway.com/payer-trade-groups/ qualitysatisfaction/quality-improvement/general-approaches/ pay-for-performance/pay-for-performance-in-medicare/) Accessed on March 13, 2018.

5. Centers for Medicare \& Medicaid Services (https:// www.cms.gov/Medicare/Medicare-Fee-for-Service-Payment/ AcutelnpatientPPS/HAC-Reduction-Program.html) Accessed on March 13, 2018.

6. Centers for Medicare \& Medicaid Services (https:// www.cms.gov/Medicare/Medicare-Fee-for-Service-Payment/ AcutelnpatientPPS/Readmissions-Reduction-Program.html) Accessed on March 13, 2018.

7. Kaiser Health News. 769 Hospitals Penalized for Patient Safety In 2017: Data Table. (https://www.cms.gov/Medicare/MedicareFee-for-Service-Payment/AcutelnpatientPPS/ReadmissionsReduction-Program.html) Accessed on March 13, 2018.

8. Jafari MD, Wexner SD, Martz JE, McLemore EC, Margolin DA, et al. (2015) Perfusion Assessment in Laparoscopic Left Sided/ Anterior Resection (PILLAR II): A Multi-Institutional Study. J Am Coll Surg 220: 82-92.

9. Starker PM, Chinn B (2017) Using outcomes data to justify instituting new technology: a single institution's experience. Surgical Endoscopy 32: 1586-1592.

10. Centers for Medicare \& Medicaid Services. MACRA: MIPS \& APMs: (https://www.cms.gov/Medicare/Quality-InitiativesPatient-Assessment-Instruments/Value-Based-Programs/ MACRA-MIPS-and-APMs/MACRA-MIPS-and-APMs.html) Accessed on March 13, 2018. 